\title{
Influence of landscape on the Argentinean white wines "terroir": cv. Torrontés Riojano
}

\author{
R. Romano ${ }^{a}$, V. Trebes, and R. Gargantini \\ Special Analytical Standards Department, Submanagment of Research for Control, National Institute of Vitiviniculture, \\ San Martín 430, Mendoza (CP 5500), Argentina
}

\begin{abstract}
There are many publications about the variables that influence the differentiation and the typicity of a "terroir". However, there are no publications that objectively determine the influence of a landscape on the "terroir".

The hypothesis that 5 odorant compounds could come from the shrub flora of vitivinicultural geographical areas has been posed.

The selected plant was jarilla (gender Larrea) and the study proceeded with leaves, stems, primary and secondary roots, flowers, pollen and fruits of jarilla in order to find in fact any of the 5 compounds.

The methodology was to analyze the odorant components of jarilla, the jarilla's surrounding soils and vines of different geographical areas, the volatile compounds absorption by the vine roots and the mechanisms of volatile compounds setting of the bloom. For all the studies, there were seventy-one volatile compounds used as variables, obtained by gas chromatography, by application of a multivariate statistical model for classification and by cluster method.

It was proved that there is a hierarchical relationship of the aromatic variables between pollen, roots and leaves of jarilla on one side, and the vineyards soils, vine blossoms and wines on the other.

This study confirms that the volatile compounds of jarilla, arrive to the vineyards in form of pollen and fruits to be later absorbed by vine roots as well as by blooms, forming so an interactive ecosystem unity.

It is concluded that the 5 volatile compounds could act as molecular markers of geographical areas.
\end{abstract}

\section{Introduction and background}

Whereas the knowledge and the competence in the international wine market advance, increase the requirements for certification of the wine quality. Nowadays, at the international level not only requires the wine should be made exclusively from fermented grape juice [1], also is included within this requirement the concepts of varietal certification and the origin of its "Terroir".

The "Terroir", as defined by the OIV (International Organization for Vine and Wine), Resolution OIV/VITI $333 / 2010$ [2], "is an unique and defined geographical space over which there is a collective understanding of the interactions between physical and biological environment and winemaking practices that apply it. These interactions reveal originality; give reputation to an originating asset of this geographical area". That is, "Terroir" means that wines from a particular area are unique and unable to be reproduced elsewhere, even though the variety and production technique is repeated exactly. "Terroir" integrates the landscape features and part of local values.

"Terroir" is a descriptive study from a site of the wine area that persists through the effects of fermentation and

\footnotetext{
${ }^{a}$ Corresponding author: raquelromano@inv.gov .ar
}

maturation of wine. Since, "Terroir" is strongly associated with geographical origin; it is difficult to quantify the influence of it in the finished product.

Although, it has been written a lot about the concept of "terroir" and the wine typicity, few attempts have been made to quantify it $[3,4]$. An interesting study showed that wines with certain origin denominations can produce a consistent and predictable level of quality, while other wines, whose origin is uncertain, not declared on label, do not do it [4]. This means that wines of the same variety but from different geographical areas are expressed differently affecting their quality.

The geographical area or "Terroir" can be seen as indicative of the aromatic typicity for a particular grape variety. Two of the most frequently asked questions are: Can different geographical areas give different types of wine on the basis of the same variety? And within a defined geographic area, is it possible to have several different aromatic expressions for the same cultivar? The answer to this is that it is possible to do it, although blind tastings have revealed the fragile and complex of product typicity. There are many publications on climatic variables, soil, altitude, agricultural practices such as driving of the vineyard, type of irrigation, and type of pruning that influence the differentiation and typing of "Terroir" [5-9].

This is an Open Access article distributed under the terms of the Creative Commons Attribution License 4.0, which permits unrestricted use, distribution, and reproduction in any medium, provided the original work is properly cited. 
Analytical characterization of the wine aroma profile allow to determinate the major volatile components that directly affect the perception of the aromas of wines and those who are below the threshold of perception [10-14]. It is n't known in which magnitude those components that are below the threshold of perception, affect the overall perception of wine aroma neither it's known if these have some direct or indirect relationship with the native flora.

There are no studies in Argentina that relate the content of wine volatile components with the geographical environment or landscape of vineyards that give to the areas the characteristics of a "Terroir". In this sense, to carry out a descriptive study of wine geographical areas of Argentina, it is observed that the vineyards are planted between 900 meters and 1500 meters approximately coinciding with the distribution of the dominant shrubs of the family Zygophyllaceae, especially of the genus Larrea (jarillas) [15-17]. Exist from the Patagonian region to the Salta Province three species of jarillas:

1. Larrea cuneifolia: its branches always oriented facing west-east; it's developed in fine-textured soils. It is considered provincial flora.

2. Larrea divaricada: fuzzy branches and adapted to sandy and deep soils.

3. Larrea nitida: softwood and shiny leaves, draws water from groundwater.

The three Jarilla species are distributed according height sea level: Larrea cuneifolia (up to $1,200 \mathrm{~m}$ ); Larrea divaricata (up to $1,500 \mathrm{~m}$ ) and Larrea nitida (from $1.500 \mathrm{~m})$.

Flowering jarillas occurs between the months of October and November, coinciding with the period of inflorescence of the vine, which may imply that there is cross-pollination, which mean the volatile compounds of jarillas pollen are adsorbed on the surface of the berries' pruine or the volatile compounds are absorbed through the soil by the roots of the vines.

The types of jarillas are characterized by been very resinous and with a lot of perfume. Therefore, there may be a relationship between jarillas and vines that explain why the same variety of wine is expressed differently according to geographical origin, giving the characteristics of a "Terroir".

\section{Objectives}

Demonstrate that it is possible to predict the geographical origin of commercial white wines of different qualities, by chromatographic analysis of aromatic compounds and the use of a statistical prediction model, based on database of unquestionable variety and geographical origin wines, generated from microvinifications standardized, giving the INV (National Institute of Viticulture) an objective tool for the control.

To find possible relationships between the volatile components that discriminate geographical areas and native flora surrounding vineyards.

Try as far as possible fixation mechanisms of volatile components from the surrounding landscape, on the pruine, fatty substance arranged as crusts on the cuticle of the berry clusters exposed to the area of influence of these flavours or through the vine roots absorption of the volatiles compounds.

\section{Materials and methods}

\section{Materials}

Grapes and Wines of Reference: It was worked on Vitis vinifera varieties, cv Chardonnay, cv. Sauvignon blanc, and cv Riojano Torrontés, microvinificadas under identical conditions of cold maceration and alcoholic fermentation. Geographical Location: Zone center, Uco Valley and East Zone of the Province of Mendoza, and geographic areas Vichigasta, Villa Union and Guandacol Center La Rioja Province.

Wine Trade: 25 commercial samples of different varieties and geographical areas referred to in their labels.

Jarillas: leaves, stems, primary and secondary roots, flowers and pollen.

Soil: surrounding land to copies of Vitis vinifera and surrounding land to the copies of the jarillas.

\section{Methods}

\section{Sampling}

The sampling of cultivars before mentioned on the geographical areas was performed by expert staff who certified the varietal origin by ampelography and sampling of cultivars genetically certificates.

\section{Microvinifications}

For winemaking of reference wines trough microvinification certain guidelines were established: 1) the quantity of grapes to produce; 2) the stalks handmade; 3) pressing under controlled conditions; 4) the alcoholic fermentation carried out with a pool of selected yeast Saccharomyces cerevisiae; 5) cold maceration and 6) conditions for cold stabilization and conservation of wines held in cold storage.

\section{Native flora}

Samples of leaves, flowers, pollen, stems and roots jarillas were taken, and extracted by system KudernaDanish concentration, the volatile components with dichloromethane azeotrope pentanediol and subsequent identification by Gas Chromatography with Mass Detector.

\section{Soil}

Following the same methodology of extraction and concentration were analyzed by gas chromatography the soil volatiles compounds near the vines and jarillales for comparison.

We assessed whether some of the volatile components that had previously discriminated wines geographical areas, coincide with those found in jarillas. 


\section{Analytical method}

For the analytical determination of selected aromatic profile, the modified method proposed by Gunata in the laboratories of INV was adopted. This method is based on the selective adsorption of the odorant compounds wine on a non ionic resin (Amberlite XAD2), further elution with an azeotropic mixture of solvent (pentane and dichloromethane) and concentration thereof. Finally, we performed quantitative determination by gas chromatography with FID detector using the Internal Standard Method (R-2-octanol). The identification of the volatiles was performed by gas chromatography with mass detector (GC-MS).

\section{Statistical methods}

To be able to realize the varietal classification should be established statistically, significant differences between varieties of wine against a set of measured variables on the wines (volatile compounds), so that in case they exist, explain in what sense are given and provide methods of systematic classification of new samples of unknown origin wines. In this work, cross-validation was used.

On data obtained the statistical analysis Statgraphics Plus 6.0 or Centurion XV Statgraphics package was made, consisting in discriminant study of variables with each individual odoriferous components from the sample, using ORIGEN as classification factor. Cluster analysis is a set of methods or statistical techniques to describe and recognize different groups that underlie a set of individuals or units of observation that is its permit classification or divided into more or less homogeneous groups, a group of individuals who are defined by different variables. The basic idea of this method is to group elements in a hierarchical way because of the variables that make up the "dendrogram" and formation of "clusters" were the volatile components that differentiated geographical areas and are found in wines, the pruine, in soils vineyards, in jarillales' floors, leaves, roots, flowers, pollen and fruit of jarillas. The ultimate goal was try to demonstrate a hierarchical relationship between the components found in jarillas and their influence on soils of vineyards, pruine and berry wines.

\section{Results}

\section{Geographical differentiation}

Using discriminant analysis, the following volatiles were obtained with discrimination ability between different geographical areas both varieties and within each variety: $\alpha$-terpineol, carvacrol, cineole, 4-terpineol, 2-isobutyl-3methoxypyrazine, 2-Isopropyl 3-methoxypyrazine, eugenol, (E)-2-Hexenol, hexanol, guaiac, Isoeugenol, Menthol, Nerol, p-Anisaldehyde, (R) -Mirtenol, (R) Nerolidol, (S) -Nerolidol, transparent and Anethole thymol.

Of the 19 components capable of discrimination, 5 (Menthol, p-Anisaldehyde, cross Anethole, Thymol and Carvacrol) have not known metabolic pathway in wine so they could come from external sources.

Perception threshold was determined by calculating the OAV (in English: Odor Activity Value).

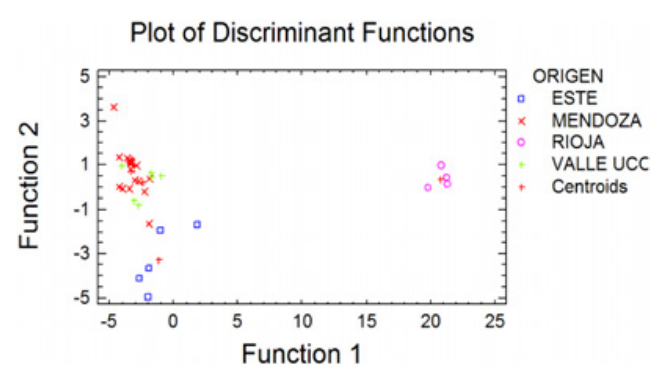

Figure 1. Discrimination of 4 geographical areas for varieties Chardonnay, Sauvignon Blanc and Rioja Torrontés.

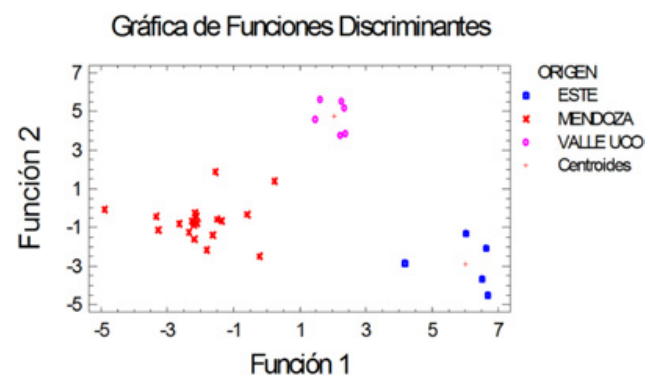

Figure 2. Discrimination of 3 geographical areas of the Province of Mendoza varieties Chardonnay, Sauvignon Blanc and Rioja Torrontés.

\section{ORIGEN vs Torrontés riojano}

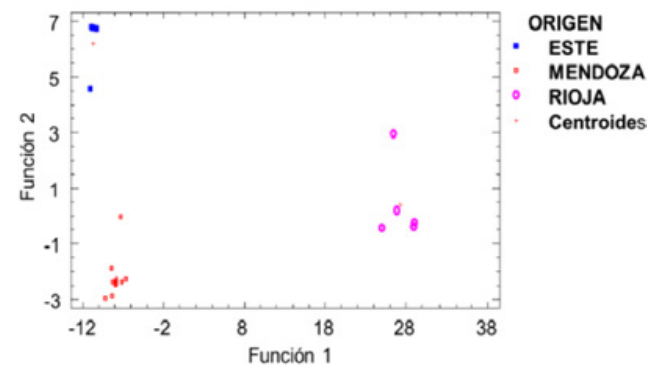

Figure 3. Discrimination of 3 geographical areas cv. Rioja Torrontés.

Discrimination these graphs shown in Figs. 1, 2 and 3 were obtained.

\section{Partial conclusion}

The discriminant variables obtained to the classification of geographical origin ( $\alpha$-terpineol, carvacrol, cineole, 4-terpineol, 2-isobutyl-3-methoxypyrazine, 2-isopropyl3-methoxypyrazine, eugenol, (E)-2-Hexenol, Hexanol, guaiac, Isoeugenol, Menthol, Nerol, p-Anisaldehyde, (R) Mirtenol, (R) -Nerolidol, (S) -Nerolidol, thymol and transanethole), discriminated geographic areas within the same variety.

Therefore it is concluded that different geographical areas or "Terroir" can give different types of wine on the basis of the same variety.

Regarding OAV studio as variety and geographical origin is concluded that the compounds trans anethole, p-Anisaldehyde, Eugenol, guaiac, thymol and cineole in variety Torrontés Riojano and particularly wines from $\mathrm{La}$ Rioja area, exceed the value of aroma. 
Table 1. Results expressed OAV volatile components of the 5 .

\begin{tabular}{|c|c|c|c|c|c|}
\hline & \multicolumn{5}{|c|}{ OAV } \\
\hline & Mentol & p-Anisaldehí & trans-Anetol & Timol & Carvacrol \\
\hline ROOTS OF JARILLAS & 8.42 & 45.6 & 0.00 & 1.91 & 1.16 \\
\hline LEAVES OF JARILLAS & 0.001 & 0.6 & 2.60 & 3.99 & 0.108 \\
\hline POLLEN OF JARILLAS & 0.23 & 0.0 & 7.24 & 10.78 & 0.24 \\
\hline FLOWERS OF JARILLAS & 0.76 & 173.8 & 352.87 & 0.0 & 5.24 \\
\hline
\end{tabular}

Table 2. Floors and floors jarillales vineyards expressed in OAV.

\begin{tabular}{|l|l|c|c|c|c|c|}
\hline & & \multicolumn{4}{c|}{ OAV } \\
\hline ORIGEN & GEOGRAPHICAL ARE & Mentol & p-Anisaldeh & trans-Anet & Timol & Carvacrol \\
\hline FLOORS JARILLALES & RIOJA & 0 & 366 & 7320 & 136.8 & 26.71 \\
\hline FLOORS JARILLALES & VALLE DE UCO & 0 & 206 & 4120 & 486 & 18.24 \\
\hline FLOORS JARILLALES & MENDOZA & 0 & 248 & 4960 & 0 & 21.18 \\
\hline FLOORS JARILLALES & ESTE & 0 & 0 & 0 & 104,6 & 10,66 \\
\hline FLOORS VINEYARDS & RIOJA & 0 & 22.2 & 444 & 370 & 10.65 \\
\hline FLOORS VINEYARDS & VALLE DE UCO & 0 & 21 & 420 & 346 & 11.53 \\
\hline FLOORS VINEYARDS & MENDOZA & 0 & 18.6 & 372 & 0 & 2.12 \\
\hline FLOORS VINEYARDS & ESTE & 0 & 10.6 & 212 & 206 & 1.10 \\
\hline
\end{tabular}

In Chardonnay only exceed the value of aroma, $p$ Anisaldehyde, Hexanol, trans-anethole and 2-isobutyl-3 methoxypyrazine, presenting more intense wines from Mendoza Province.

In variety Sauvignon blanc, the Hexanol compounds, trans Anethole, Eugenol, Guaiacol, 2-isobutyl3-methoxypyrazine and 2-isopropyl-3-methoxypyrazine exceed the value of scent especially in the wines from Mendoza.

The reaminder of the variables that do not exceed the value of aroma, only contribute to the formation of "Terroir".

We conclude that, within the same cultivar, different aromatic expressions according to the "Terroir" of origin are obtained.

Therefore the volatiles compounds that make up a "Terroir" have a decisive influence on the typicality of wines, either aromas that may or may not be perceived even if the cultivar is the same.

\section{Results for types of jarillas}

It is found in all parts of jarilla the 19 components that differentiate geographical areas. Are shown in Table 1 the results expressed in the $5 \mathrm{OAV}$ volatile components.

\section{Results of vineyard soils and soils jarillas}

It's shown in Table 2 shows the results obtained on soils and soils of vineyards jarillales expressed in OAV.

As can be seen, except that Menthol was not found in any soil and Thymol which was not found in jarillas soils and vineyards soils in the area of Mendoza, the other variables exceed the value of OAV.

The p-Anisaldehyde was more intense in soils of La Rioja, in Valle de Uco, Mendoza and East Zone respectively in both floors of jarilla and vineyards.

The trans-anethole obtained high odorant intensity in both floors in the La Rioja area, while it was found more odorant intensity in Mendoza than Uco Valley in jarillales floors, keeping a decreasing ratio from La Rioja, Valle de Uco, Mendoza and East Zone in vineyard soils.

The Thymo, except jarillales and vineyards soils of Mendoza area, the theoretical descending order of its odoriferous intensities was respected other geographical areas.

\section{Test of absorption by roots and adsorption on pruinas}

About two species of Vitis vinifera variety Torrontés Riojano, separated by ten meters the following test was performed to check for uptake by roots and transfer the volatile compounds to berries that previously discriminated geographical areas.

1 - One specie was irrigated by flooding with a solution of volatile components and absorption followed up was performed since sprouting to the formation of the berries.

2 - The other specie was irrigated with the same amount of water without the volatile components (blind trial).

3 - The volatile components from the pruine berries were isolated, by scraping or by berries immersion in water and subsequent extraction with pentane-dic hloromethane. Concentration and identification of vol atile components were made by gas chromatography.

In this pilot assay it showed that is possible the absorption by the roots via the soil diffusion of volatile compounds, the molecular weights were in the range of approximately 100 to 230 , and transported systemically to the branches.

Of the 5 compounds from jarilla, the thymol was the only compound that didn't show absorption and menthol was absorbed only until the second week, according to observations in Fig. 4.

\section{Assay on pruine of cv. Rioja Torrontés}

The 5 components were found in similar concentrations on pruine and generally agreed with most shrub density 
Table 3. Absorption of volatile compounds by roots of Rioja Torrontés.

\begin{tabular}{|l|l|l|l|l|l|}
\hline $\mathbf{m g} / \mathbf{L}$ & volatile components & 1 week & 2 week & 3 week & 4 week \\
\hline 0.27 & Guayacol & 1.04 & 0.75 & 0.25 & 0.05 \\
\hline 0.3 & Timol & 0.0 & 0.0 & 0.0 & 0.0 \\
\hline 0.25 & trans-Anetol & 2.35 & 1.28 & 0.18 & 0.0 \\
\hline 0.27 & 4- Terpineol & 0.85 & 0.29 & 0.09 & 0.0 \\
\hline 0.25 & Mentol & 0.0 & 0.1 & 0.0 & 0.0 \\
\hline 0.43 & Carvacrol & 1.32 & 1.25 & 0.56 & 0.01 \\
\hline 0.23 & 2-Isopropil-3-metoxip & 0.36 & 0.22 & 0.0 & 0.0 \\
\hline 0.18 & Isoeugenol & 2.82 & 1.85 & 0.63 & 0.23 \\
\hline 0.31 & p- Anisaldehído & 1.89 & 1.23 & 0.7 & 0.05 \\
\hline 0.2 & (E )-2- Hexenol & 15.2 & 12.8 & 10.8 & 9.8 \\
\hline 0.34 & Hexanol & 2.36 & 2.26 & 2.1 & 1.89 \\
\hline 0.29 & (R )- Mirtenol & 1.06 & 0.23 & 0.09 & 0.0 \\
\hline 0.3 & R y S- Nerolidol & 11.03 & 8.6 & 7.8 & 8.1 \\
\hline 0.37 & Nerol & 0.43 & 0.22 & 0.07 & 0.0 \\
\hline
\end{tabular}

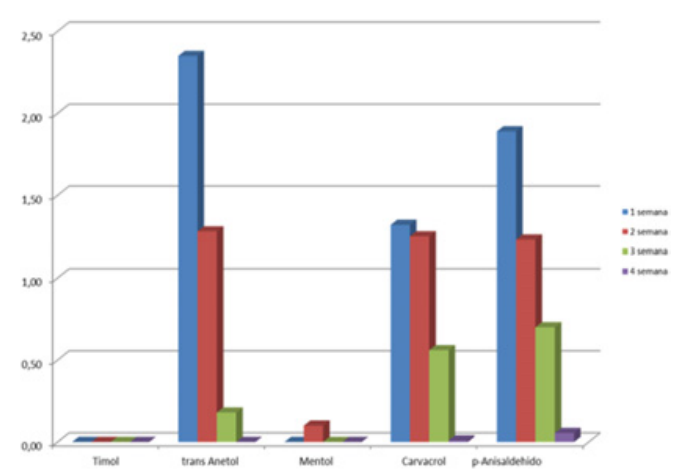

Figure 4. Absorption roots for 4 weeks.

located in the province of La Rioja, in smaller amounts were founded in the Uco Valley and finally in Mendoza area, except for Carvacrol was found in greater proportion in Valle de Uco, as shown in Table 4.

The calculation of OAV a value of 16.44 for transAnethole was obtained in the pruine of La Rioja, enough to cause odor impact. The other compounds did not exceed the value of aroma.

Table 4: Compounds found in Rioja Torrontés pruinas 3 geographical areas.

\section{Interaction between jarillas and vines. Cluster analysis}

To relate the volatile components as a unit interactive ecosystem formed by the possible absorption through the soils impregnated with odoriferous compounds and the moving through the wind of pollen, flowers and fruits of jarillas to the geographical area of influence, we proceeded to study a possible relationship through cluster analysis.

The ultimate goal was try to demonstrate a hierarchical relationship between the components found in jarillas and influence in pruine berries and wines.

\section{Interaction between jarillas and vines. Cluster} analysis

To relate the volatile components as a unit interactive ecosystem formed by the possible absorption through the soils impregnated with odoriferous compounds and the
Table 4. Compounds found in Rioja Torrontés pruinas 3 geographical areas.

\begin{tabular}{|c|c|c|c|}
\hline AROMS & MENDOZA & RIOJA & VALLE DE UCO \\
\hline Mentol & nd & 0,003 & 0 \\
\hline p-Anisaldehído & 0.66 & 0,508 & 0 \\
\hline Transanetol & nd & 16,44 & 0,746 \\
\hline Timol & nd & 0,518 & 0,24 \\
\hline Carvacrol & nd & nd & 0,0426 \\
\hline
\end{tabular}

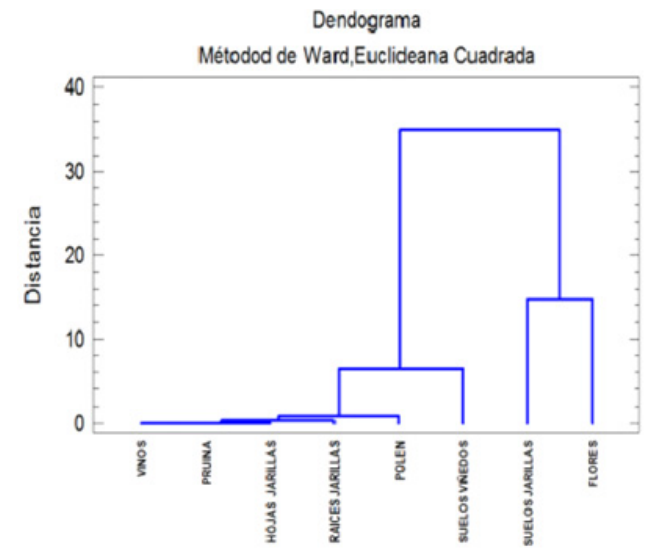

Figure 5. Relationships between wine and bloom, soil and jarillas.

moving through the wind of pollen, flowers and fruits of jarillas to the geographical area of influence, we proceeded to study a possible relationship through cluster analysis.

The ultimate goal was try to demonstrate a hierarchical relationship between the components found in jarillas and influence in pruine berries and wines.

In Table 5 overall results expressed in OAV is.

By analyzing the conglomerates "dendrogram" was obtained, shown below in Fig. 5.

Most related resulted been the wines with the way coating and they are strung with leaves, roots jarillas, pollen and soils of vineyards. Less important is the association between floors jarillas and flowers. 
Table 5. Relationship between wine and pruine with soils and jarillas.

\begin{tabular}{|c|c|c|c|c|c|}
\hline & Mentol & p- Anisaldehído & trans-Anetol & Timol & Carvacrol \\
\hline WINES & 0.007 & 2.115 & 0.499 & 0.07 & 0.053 \\
\hline PRUINE & 0.001 & 0.163 & 5.949 & 0.25 & 0.010 \\
\hline FLOORS JARILLALES & 0.000 & 205.000 & 368.638 & 181.85 & 19.195 \\
\hline FLOORS VINEYARDS & 0.000 & 18.100 & 81.075 & 230.50 & 6.349 \\
\hline ROOTS OF JARILLAS & 8.42 & 45.670 & 0.000 & 1.91 & 1.157 \\
\hline LEAVES OF JARILLAS & 0.010 & 0.600 & 2.600 & 4.00 & 0.107 \\
\hline FLOWERS OF JARILLAS & 0.760 & 173.800 & 352.872 & 0.00 & 5.244 \\
\hline POLEN & 0.228 & 0.000 & 7.240 & 10.78 & 0.243 \\
\hline
\end{tabular}

Clearly formed two clusters: the first relates flowers with jarillas floors and the second is formed by a chain from vineyard soils, pollen on roots, leaves, pruine and wines.

\section{Conclusion}

It's concluded that from cluster analysis with aromatic variables there is a relationship between pollen, roots and leaves of jarillas with soils of vineyards, wines and pruine.

This study should confirm that volatile compounds from jarillas goes to vineyards through pollen and fruits and be then absorbed by roots and vines by adsorption on pruine to finally get into the wines, forming interactive ecosystem unit by the transfer of pollen and fruit through the wind toward geographical area of influence.

\section{References}

[1] Rapp, A.: Volatile flavour of wine: Correlation between instrumental analysis and sensory perception. Nahrung, 42 pp. 351a 363. (1998)

[2] Rapp, A., y Mandery, H.: Wine aroma. Esperientia, 42 pp. 873 a 884. (1986)

[3] Guadagni, D.G., Buttery, R. G. y Okano, S.: Odour thresholds of some organic compounds associated with flavours. J. Sci. Food Agric., 14 pp. 761 a 765. (1963)

[4] Pérez-González, J. A., González, R., Querol, A., Sendra, J. M., Ramón, D.: Construction of a recombinant wine yeast expressing beta-(1-4)endoglucanase and its use in microvinification processes. Appl. Environ. Microbiol., 59 pp. 28001 a 28006. (1993)
[5] Instituto Nacional de Vitivinicultura. República Argentina. Resolución N ${ }^{\circ}$ C.20 -2004

[6] Gunata, Y.Z., Bayonove, C.L.,Baumes, R.L., Cordonnier, E.: Stability of free and boundfractions of aroma components of grapes c.v. Muscat during the wine processing: preliminary results. Am. J. Eno. Vitic., 37 (1986)

[7] Uriel, E.: "Data Analysis: Temporary Series and Multivariate Analysis"; AC Ed. (1995)

[8] Douglas G. A., J Martin B.: "Comparing several groups using Analysis of variance" BMJ; 312 pp. 1472 a 1473. (1996)

[9] Van Leeuwen, C. and Seguin, G.: The concept of Terroir in viticulture. Journal of Wine Research. 17: 1-10. (2006)

[10] Togores, J.H. Tratado de Enología, España; MundiPrensa Libros, Volumen I y II (2003)

[11] Dubois, P.: Les arômes des vins et leurs défauts. Revue Française dÓenologie. (145):27-39; y (146): 39-50. (1994)

[12] Du Plessis, C.S.: Influence de la température délaboration et de conservation sur les caractéristiques physico-chimiques et organoleptiques des vins. Bull. OIV. (624):105-115. (1983)

[13] Schlosser J., Reynolds A.G, King M., Cliff M.: Canadian Terroir: sensory characterization of Chardonnay in the Niagara peninsula. Food Research International. (38):11-18. (2005)

[14] http://www.inv.gov.ar/PDF/ResolucionesC/ 2004/ResolucionC20-2004.pdf

[15] http://www.ipni.org/index.htm. The International Plant Names Index

[16] http://www.cricyt.edu.ar/ladyot/herba_digi tal/fichas_especies/jarilla_cunei.htm.

[17] Herbario digital. Ladyot- Iadiza. (2006). http://www.cricyt.edu.ar/ladyot/ 